\title{
Retinal Detachment with an Unusual Shape
}

\author{
Marco Luigetti ${ }^{1}$, Dario Marangoni ${ }^{2}$, Stefano Bartoletti ${ }^{3}$, Mario Sabatelli ${ }^{1}$ \\ and Alessandro Cianfoni ${ }^{4}$
}

Key words: retinal detachment, magnetic resonance, visual impairment

(Inter Med 48: 1777-1778, 2009)

(DOI: 10.2169/internalmedicine.48.2630)
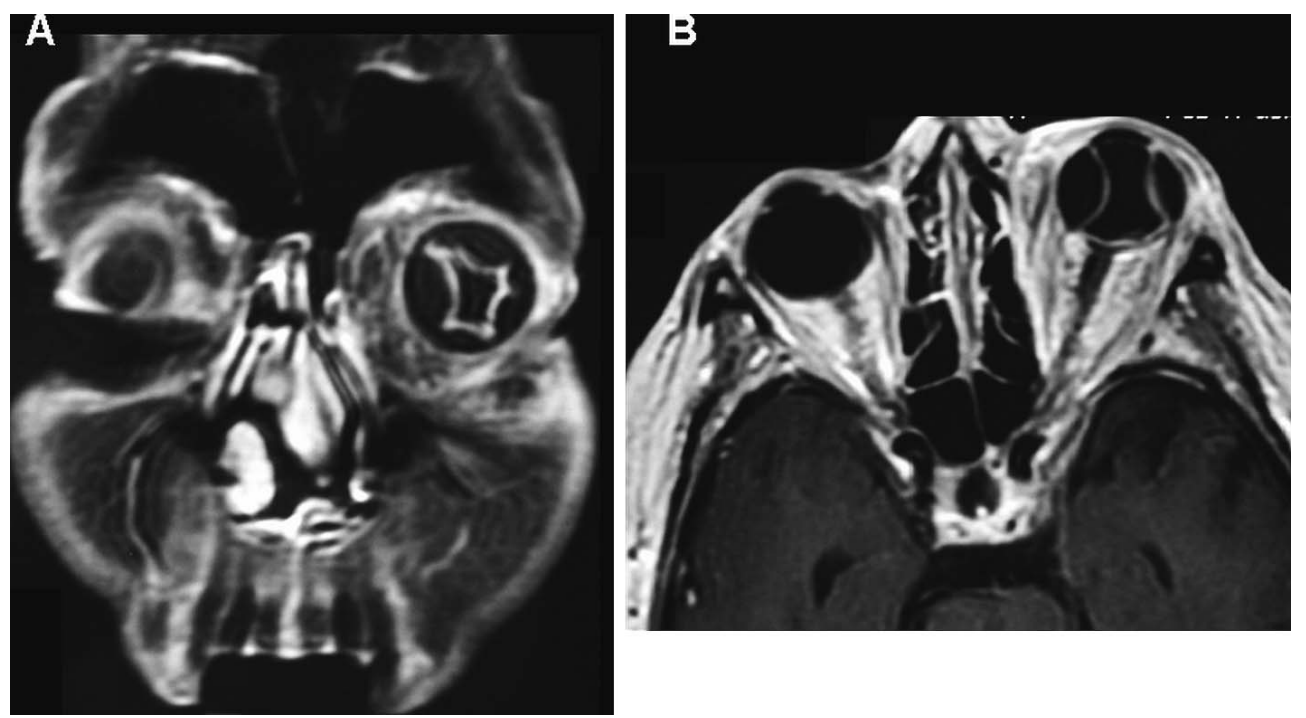

Picture 1. Coronal fat-suppressed (A), and axial-enhanced T1-W images through the globes show retinal and choroidal detachment in the left eye, producing the bizarre appearance of a starshaped vitreous body on the coronal view, and of a tennis ball on the axial view. No ocular or retrobulbar masses are evident.

Retinal detachment is a relatively uncommon and largely preventable cause of vision loss.

Risk factors for retinal detachment include advanced age, previous cataract surgery, high myopia, trauma, and diabetes, as well as intraocular inflammatory diseases and neoplasms (1). A 62-year-old woman presented with a 6-week history of blurred vision in her left eye. Fundus examination of the left eye revealed a sub-total retinal detachment of un- clear cause. Magnetic resonance imaging of the brain and orbits showed an unusual appearance of retinal detachment, resulting in a star-shaped vitreous body, as evident on this T1-weighted image (Picture 1); there was no evidence of neoplasm or inflammation $(2,3)$. Although the patient underwent surgery, her vision remained restricted to lights and shadows.

\section{References}

1. Gariano RF, Kim CH. Evaluation and management of suspected retinal detachment. Am Fam Physician 69 (7): 1691-1698, 2004.
2. Ng J, Cleland J, Bergin P. Retinal detachment. Lancet 362 (9384): 639, 2003.

\footnotetext{
${ }^{1}$ Department of Neurology, Catholic University of Sacred Heart, Rome, Italy, ${ }^{2}$ Department of Ophthalmology, Catholic University of Sacred Heart, Rome, Italy, ${ }^{3}$ Department of Cardiovascular Medicine, Catholic University of Sacred Heart, Rome, Italy and ${ }^{4}$ Neuroradiology Section Radiology Department, Medical University of South Carolina MUSC, Charleston-SC, U.S.A.

Received for publication June 27, 2009; Accepted for publication July 3, 2009

Correspondence to Dr. Marco Luigetti, mluigetti@gmail.com
} 
Inter Med 48: 1777-1778, 2009 DOI: 10.2169/internalmedicine.48.2630

3. Nölte I, Brockmann MA. Images in clinical medicine. Magnetic

e18, 2007. resonance imaging of retinal detachment. N Engl J Med 357 (17):

(C) 2009 The Japanese Society of Internal Medicine http://www.naika.or.jp/imindex.html 